\title{
ÁCIDO ASCÓRBICO NA REDUÇÃO DO ESCURECIMENTO DO PERICARPO E NA QUALIDADE PÓS-COLHEITA DE LICHIA
}

Danielle Fabíola Pereira da Silva ${ }^{1}$, Leila Cristina Rosa de Lins², Rosana Gonçalves Pires Matias ${ }^{3}$, Robson Ribeiro Alves $^{4}$, Luiz Carlos Chamhum Salomão ${ }^{5}$

\section{RESUMO}

O pericarpo da lichia escurece rapidamente após a colheita, o que é atribuído à degradação da antocianina. O objetivo desta pesquisa foi avaliar o efeito de diferentes doses de ácido ascórbico na prevenção do escurecimento do pericarpo e na manutenção da qualidade pós-colheita de lichia. Frutos de lichieira 'Bengal' com o pericarpo completamente vermelho foram imersos em soluções com diferentes concentrações de ácido ascórbico $(0 ; 3 ; 6 ; 9 ; 12$ e 15\% p/v), por 5 minutos. Após secagem à temperatura ambiente, foram acondicionados em bandejas de poliestireno expandido, recobertos com filme de PVC, armazenados em temperatura ambiente e avaliados a cada 2 dias, durante 8 dias. As perdas de massa variaram de 9,2 a $10,46 \%$ no $8^{\circ}$ dia de armazenamento. Independentemente da dose, o ácido ascórbico não foi eficiente na prevenção do escurecimento do pericarpo da lichia 'Bengal', sendo que, até o quarto dia de armazenamento, os frutos tratados permaneceram semelhantes aos frutos do tratamento controle e, a partir deste dia os frutos controle escureceram menos que os tratados com ácido ascórbico.

Palavras-Chave: Litchi chinensis Sonn., escurecimento do pericarpo, conservação

\section{ABSTRACT \\ ASCORBIC ACID IN REDUCING PERICARP BROWNING AND POSTHARVEST QUALITY OF LYCHEE}

The lychee pericarp becomes brown only a few days after harvest due to the degradation of anthocyanins. The objective of this study was to evaluate the effect of different concentrations of ascorbic acid in preventing pericarp browning and in maintenance of postharvest quality of lychee. 'Bengal' lychee fruits with completely red pericarp were immersed in solution with different concentrations of acid ascorbic $(0,3,6,9,12$ and $15 \%)$ for 5 minutes. After drying at room temperature, the fruits were placed on polystyrene trays and stored at room temperature and analyzed every 2 days for 8 days. Weight losses ranged from 9.2 to $10.46 \%$ on the 8 th day of storage. Independent of the dose, ascorbic acid was not effective in preventing browning of pericarp from the 'Bengal' lychee, and by the fourth day of storage the treated fruits remained similar to the control treatment, and from this day on the control fruits darkened less than those treated with ascorbic acid.

Keywords: Litchi chinensis Sonn., pericarp browning, conservation

Recebido para publicação em 18/06/2012. Aprovado em 13/08/2012.

1 - Engenheira Agrônoma - Pós-Doutoranda (Bolsista PNPD-CAPES)- Depto. de Fitotecnia - UFV, E-mail: - danieele@ufv.br

2 - Engenheira Agrônoma - Doutoranda (Bolsista CNPq)- Depto. de Fitotecnia - UFV, E-mail: leila.lins@ufv.br

3 - Engenheira Agrônoma - Doutora em Genética e Melhoramento - Depto. de Fitotecnia - UFV, E-mail: rosana.pires@ufv.br

4 - Químico - Mestre em Fitotecnia - Laboratorista do Depto. de Fitotecnia - UFV, E-mail: robson@ufv.br

5 - Engenheiro Agrônomo - Professor - Depto. de Fitotecnia - UFV, E-mail: 1salomao@ufv.br 


\section{INTRODUÇÃO}

A lichieira (Litchi chinensis Sonn.), pertencente à família Sapindaceae, é originária do sul da China e norte do Vietnã, onde vem sendo cultivada por mais de 3000 anos (MENZEL, 2001). Seu fruto é uma drupa de forma redonda a oval, que apresenta polpa translúcida, doce e suculenta; seu pericarpo é fino, duro e indeiscente, de cor vermelha muito atrativa. Porém, uma vez colhido e mantido sob condições ambientais, o fruto perde estas qualidades em apenas dois dias, além de ocorrer escurecimento do seu pericarpo, o que reduz o valor comercial da fruta e limita sua comercialização (DEL AGUILA et al., 2009).

O escurecimento do pericarpo de lichias está relacionado com a dessecação do mesmo, ataque de patógenos, estresses por altas temperaturas, danos por frio, senescência, dentre outros fatores que levam à degradação da antocianina por enzimas oxidativas, tais como a polifenoloxidase (PPO), peroxidase (POD) e ácido ascórbico oxidase (MIZOBUTSI et al., 2010). Relata-se, também, que o escurecimento da casca é devido ao colapso celular, que permite o contato das enzimas com seus substratos, resultando em oxidação destes na presença de oxigênio e produção de substâncias com coloração escura (LICHTER et al., 2000). Por esta razão, retardar ou reduzir a oxidação enzimática é uma importante estratégia pós-colheita para aumentar o período de armazenamento e preservar a qualidade comercial de lichias (HOJO et al., 2011).

$\mathrm{O}$ efeito benéfico do ácido ascórbico na redução do escurecimento do pericarpo de frutos, em geral, se atribui a vários aspectos, sendo um destes o efeito da captação de oxigênio e proteção, formando uma barreira que impede a difusão do oxigênio para o interior do produto, reduzindo as quinonas geradas e inibindo as PPOs (ARTES et al., 1998).

O objetivo desta pesquisa foi avaliar o efeito de diferentes concentrações de ácido ascórbico na prevenção do escurecimento do pericarpo e na manutenção da qualidade pós-colheita de lichia.

\section{MATERIAL E MÉTODOS}

Frutos de lichieira 'Bengal' com pericarpo completamente vermelho foram colhidos, no período da manhã, em janeiro de 2012, de plantas do Pomar Experimental da Universidade Federal de Viçosa, em Viçosa, Minas Gerais $\left(21^{\circ} 07^{\prime} \mathrm{S}\right.$, $42^{\circ} 57^{\prime} \mathrm{W}, 651 \mathrm{~m}$ de altitude).

Foram selecionados os frutos com pericarpo uniformementevermelho e comausência de injúrias. $\mathrm{Na}$ sequência, foram lavados em água corrente, sanificados com hipoclorito de sódio a $200 \mathrm{mg} \mathrm{L}^{-1}$, por 5 minutos e imersos nas seguintes concentrações de ácido ascórbico: $0 \%$ (controle); 3,0\%; 6,0\%; $9,0 \% ; 12,0 \%$ e $15,0 \% \mathrm{p} / \mathrm{v}$ por 5 minutos e secos à temperatura ambiente. $\mathrm{O}$ tratamento controle foi constituído de frutos lavados e sanificados. Em seguida, os frutos foram acondicionados em bandejas de poliestireno expandido (150 $\mathrm{mm} \times 150$ $\mathrm{mm} \times 25 \mathrm{~mm}$ ) e recobertos com filme de policloreto de vinila (PVC) de $12 \mu \mathrm{m}$ de espessura. A fim de simular o comércio, os frutos foram armazenados em bancada de laboratório a $19 \pm 2,4{ }^{\circ} \mathrm{C}$ e $75 \pm 5 \%$ de UR e avaliados a cada 2 dias, durante 8 dias.

Foram avaliados perda de massa fresca, atributos de cor do pericarpo, teor de sólidos solúveis e acidez titulável da polpa e teor de ácido ascórbico do pericarpo e da polpa. A perda de massa fresca foi determinada por gravimetria, sendo os resultados expressos em porcentagem de perda de massa. A coloração do pericarpo foi determinada por reflectometria, utilizando reflectômetro Minolta (Color Reader CR- 10). Foram feitas duas leituras por fruto em posições diametralmente opostas. A partir das leituras de $L^{*}, a^{*}$ e $b^{*}$, foram determinados a diferença de cor $(\Delta \mathrm{E})$ e o ângulo hue $\left(\mathrm{h}^{\circ}\right)$ que indica $\left(0^{\circ}=\right.$ vermelho; $90^{\circ}=$ amarelo; $180^{\circ}=$ verde; $270^{\circ}=$ azul). Para cálculo do $\Delta \mathrm{E}$, utilizou-se a equação:

$\Delta \mathrm{E}=\left(\Delta \mathrm{L}^{2}+\Delta \mathrm{a}^{2}+\Delta \mathrm{b}^{2}\right)^{1 / 2}$

em que,

$\Delta \mathrm{E}=$ diferença de cor entre o dia zero e cada dia de análise;

$\Delta \mathrm{L}=$ diferença da coordenada $\mathrm{L}$ entre o dia zero e cada dia de análise;

$\Delta \mathrm{a}=$ diferença da coordenada a entre o dia zero e cada dia de análise; e

$\Delta \mathrm{b}=$ diferença da coordenada $\mathrm{b}$ entre o dia zero e cada dia de análise. 
Sendo que o $\Delta \mathrm{E}$ (diferença de cor) define a saturação e intensidade da cor definida por L*, $\mathrm{a}^{*}$ e b* (MINOLTA CORP, 1994) e determinada pela diferença de cor entre os valores registrados nos frutos em cada tempo de armazenamento e os obtidos nos frutos por ocasião da colheita. Foram feitas duas leituras das coordenadas L, $a^{*}$ e b* na casca, sendo uma leitura de cada lado diametralmente oposto do fruto. O coeficiente $\mathrm{L}$ (luminosidade) varia de 0 (preto) a 100 (branco); o $a^{*}$ varia do verde $(-60)$ ao vermelho $(+60)$; o b* vai do azul $(-60)$ ao amarelo $(+60)$.

$\mathrm{O}$ teor de sólidos solúveis da polpa foi determinado com o auxílio de um refratômetro digital em amostras de polpa trituradas em liquidificador (AOAC, 1997). A acidez titulável da polpa foi determinada por titulação com $\mathrm{NaOH}$ $0,1 \mathrm{~mol}_{\mathrm{c}} \mathrm{L}^{-1} \mathrm{e}$ expressa em porcentagem de ácido málico (AOAC, 1997). O teor de ácido ascórbico do pericarpo e da polpa foi determinado por titulação com reagente de Tillman [2,6 diclorofenolindofenol (sal sódico) a 0,1\%] (AOAC, 1997). Os resultados foram expressos em mg. $100 \mathrm{~g}^{-1}$ de polpa.

$\mathrm{O}$ experimento foi conduzido em parcela subdividida, tendo-se na parcela as seis concentrações de ácido ascórbico e, na subparcela, os cinco períodos de amostragens, sendo a unidade experimental constituída por cinco frutos. $\mathrm{O}$ delineamento experimental foi o inteiramente casualizado, com três repetições. Os dados foram analisados por meio das análises de variância e regressão, usando-se o programa SAEG 9.1 Sistema para Análises Estatísticas e Genéticas (SAEG, 2007).

\section{RESULTADOS E DISCUSSÃO}

A perda de massa fresca aumentou de forma linear ao longo dos dias de armazenamento (Figura 1A). As perdas variaram de 9,2 a $10,46 \%$ no $8^{\circ}$ dia de armazenamento, valores correspondentes às doses 3 e $0 \%$, respectivamente. De acordo com Hojo et al. (2011), maiores perdas de massa significam também maior escurecimento da casca, resultado indesejável para comercialização destes frutos. Chen et al. (2001) relatam que a perda de massa superior a $18,21 \%$ é suficiente para causar escurecimento total do pericarpo de lichias, enquanto Bryant (2004) considera que perda de 3-5\% pode causar este efeito.

Houve redução na luminosidade ( $\left.\mathrm{L}^{*}\right)$ do pericarpo em todos os tratamentos (Figura 1B). No quarto dia de armazenamento, o valor médio para a coordenada $\left(\mathrm{L}^{*}\right)$ nos frutos do tratamento controle foi de 47,18 . Nos frutos tratados com a maior dose de ácido ascórbico (15\%), o valor médio foi de 46,70 no quarto dia. No oitavo dia de armazenamento os valores foram de 44,69 e 37,03 , para o controle e $15 \%$ de ácido ascórbico, respectivamente, evidenciando que a tendência de queda foi menos expressiva nos frutos do tratamento controle.
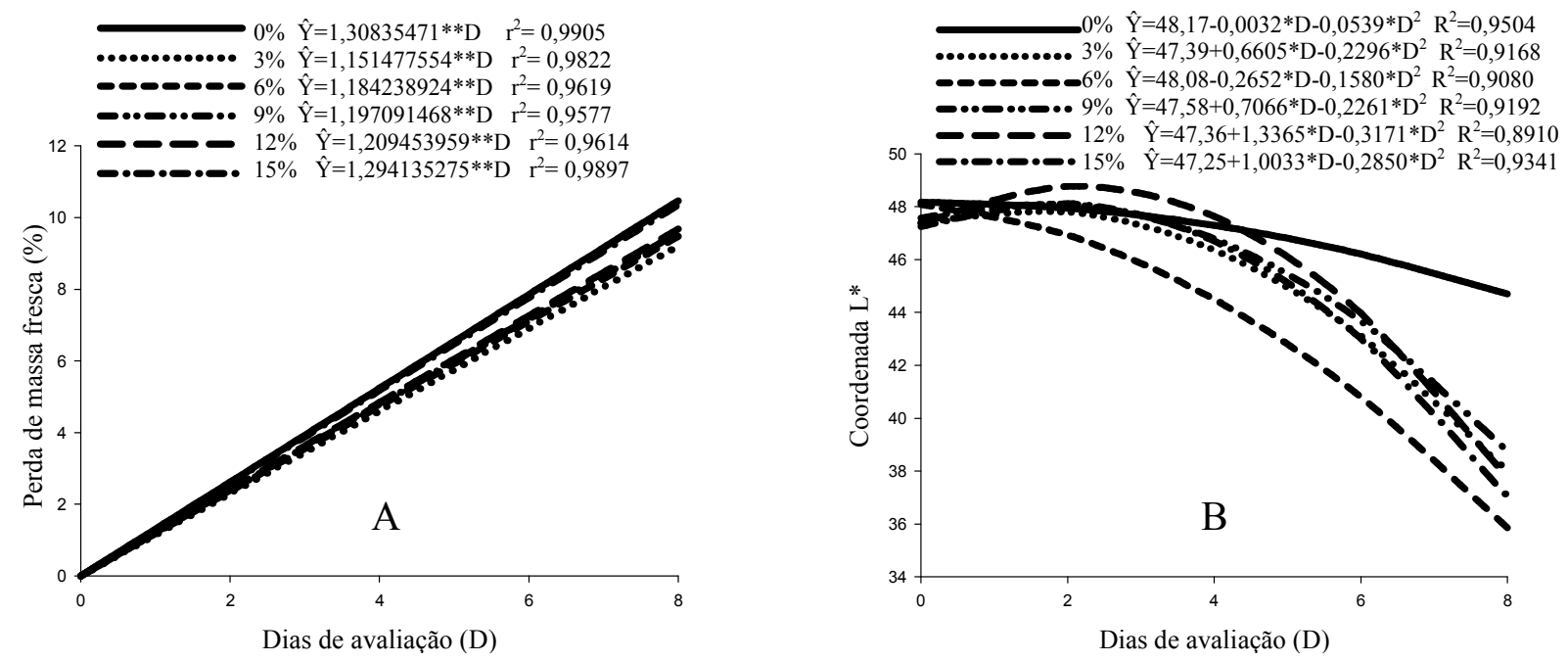

Figura 1. Perda de massa fresca (A) e coordenada $L^{*}$ do pericarpo (B) de lichias 'Bengal' submetidas aos tratamentos com ácido ascórbico e armazenadas a $19 \pm 2,4{ }^{\circ} \mathrm{C}$. 
Nos frutos tratados com 15\% de ácido ascórbico houve menor variação do ângulo hue $\left(h^{\circ}\right)$, que passou de 32,7 no dia zero para 38,3 no $8^{\circ}$ dia de armazenamento (Figura 2A). As doses menores do ácido não foram eficientes em impedir o escurecimento do pericarpo, fato comprovado tanto pelo decréscimo da luminosidade ( $\left.\mathrm{L}^{*}\right)$, quanto pelo aumento dos valores de $\mathrm{h}^{\circ}$.

Até o quarto dia de armazenamento, a mudança de cor foi mais expressiva nos frutos do tratamento controle. A partir deste dia, os frutos tratados com ácido ascórbico escureceram rapidamente, como se nota pela rápida mudança de cor em relação ao dia zero, principalmente nos frutos tratados com 6\% de ácido ascórbico (Figura 2B). Silva et al. (2010), trabalhando com lichias 'Bengal" tratadas com 0,5 , 10, 15 e $30 \mathrm{~mm}$ de ácido ascórbico, observaram que as baixas concentrações testadas não foram eficientes na prevenção do escurecimento do pericarpo.

O teor de sólidos solúveis ( ${ }^{\circ}$ Brix) apresentou tendência de queda ao longo do período de armazenamento, entretanto, nos frutos tratados com $12 \%$ de ácido ascórbico, essa queda foi mais acentuada (Figura 3A). Também houve decréscimo na acidez titulável durante o armazenamento dos frutos, sendo a tendência de queda mais expressiva quando os frutos foram tratados com 3\% de ácido ascórbico (Figura 3B). Essa tendência, em ambas variáveis, indica que os açúcares e ácidos orgânicos foram utilizados como substratos respiratórios e como esqueletos de carbono para a síntese de novos compostos durante o armazenamento dos frutos (CHITARRA; CHITARRA, 2005).

Os frutos tratados com 9, 12 e 15\% de ácido ascórbico não apresentaram reduções significativas no teor de ácido ascórbico do pericarpo ao longo do período de armazenamento (Figura 4A), o que demonstra que o ácido aplicado nos frutos foi retido no pericarpo dos mesmos. Nos demais tratamentos, houve tendência de queda, sendo que esta foi bem mais expressiva no tratamento controle. Este comportamento é explicado por Underhill e Critchley (1993), que relatam aumento na oxidação do ácido ascórbico no pericarpo de lichia durante o escurecimento.

Houve redução no teor de ácido ascórbico da polpa ao longo do armazenamento (Figura 4B), sendo que uma menor redução foi observada nos frutos tratados com $15 \%$ de ácido ascórbico, provavelmente porque o ácido aplicado sobre o pericarpo em maior concentração foi parcialmente absorvido pelos frutos. Foyer et al. (1994) explicaram que, durante a senescência, o ácido ascórbico do fruto é utilizado em reações oxidativas, que são ativadas pelos estresses sofridos pelas membranas celulares durante este período.
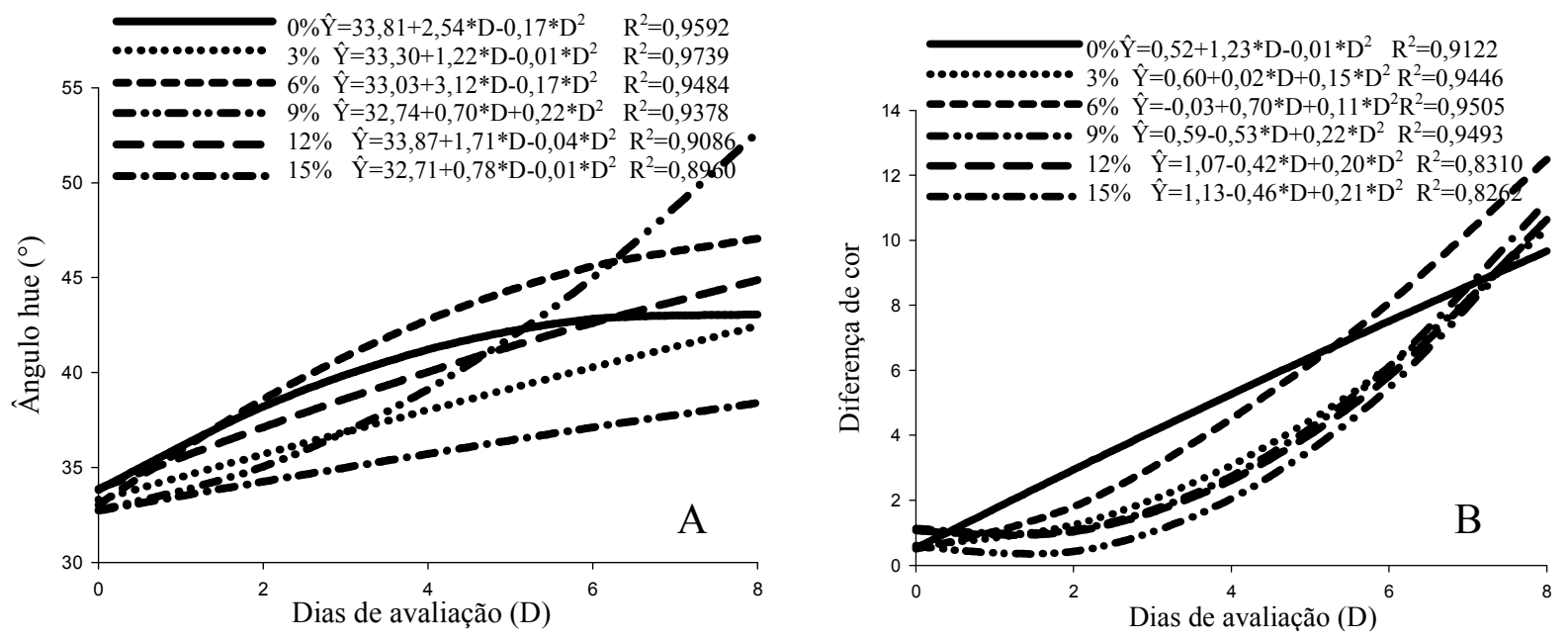

Figura 2. Ângulo hue do pericarpo (A), diferença de cor do pericarpo (B) de lichias 'Bengal' submetidas aos tratamentos com ácido ascórbico e armazenadas a $19 \pm 2,4^{\circ} \mathrm{C}$. 

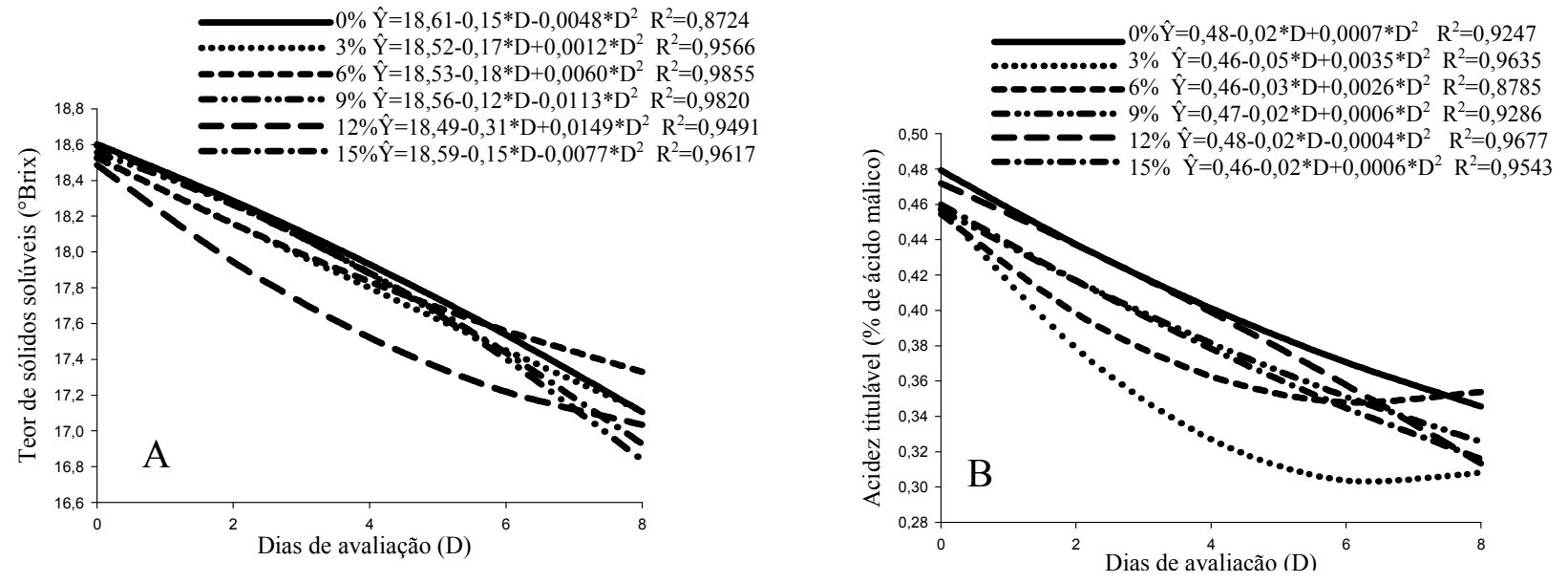

Figura 3. Teor de sólidos solúveis (A) e acidez titulável (B) da polpa $(\mathrm{H})$ de lichias 'Bengal' submetidas aos tratamentos com ácido ascórbico e armazenadas a $19 \pm 2,4{ }^{\circ} \mathrm{C}$.
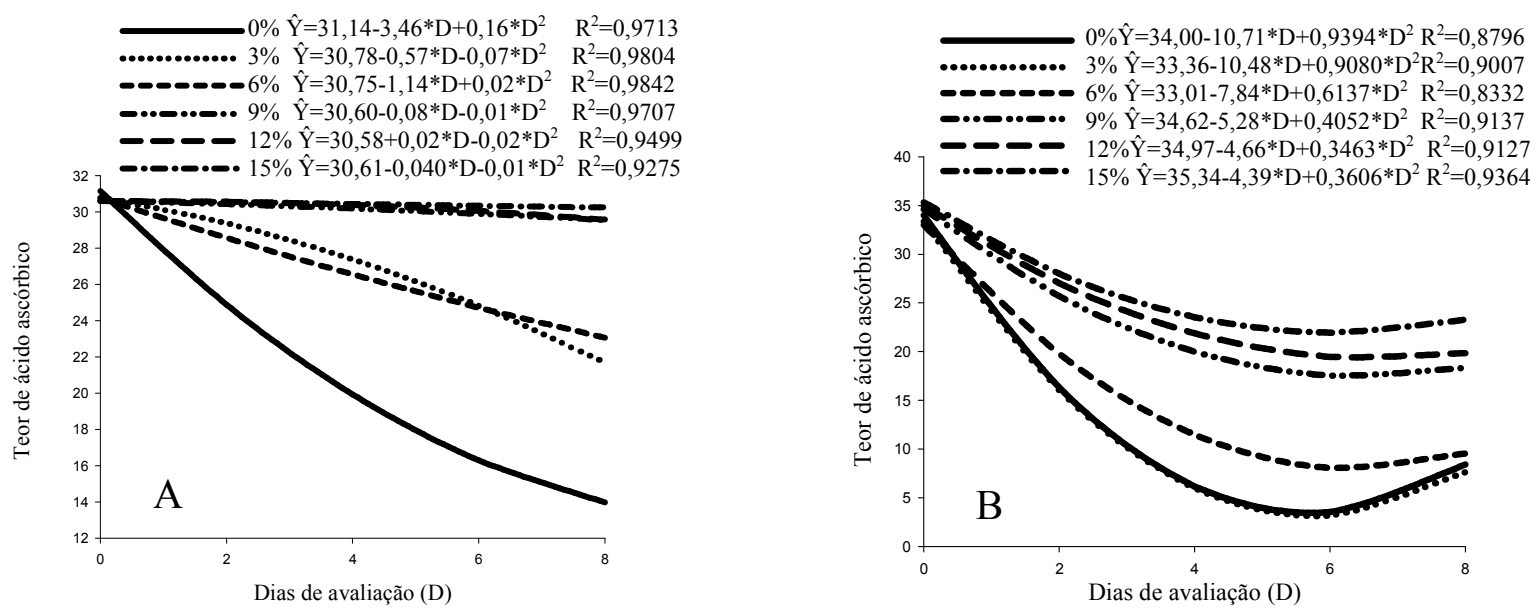

Figura 4. Teor de ácido ascórbico do pericarpo $(\mathrm{G})$ e teor de ácido ascórbico da polpa $(\mathrm{H})$ de lichias 'Bengal' submetidas aos tratamentos com ácido ascórbico e armazenadas a $19 \pm 2,4{ }^{\circ} \mathrm{C}$.

\section{CONCLUSÃO}

A aplicação pós-colheita de ácido ascórbico, independente da concentração, foi efetiva em retardar o escurecimento do pericarpo de frutos de lichia 'Bengal' até o quarto dia de armazenamento, mantendo a qualidade pós-colheita dos frutos até o final do armazenamento.

\section{REFERÊNCIAS BIBLIOGRÁFICAS}

AOAC. Official methods of analysis of the Association of Official Analytical Chemists
International. 16. ed. Washington, v.2, p.37-10, 42-2, 44-3, 45-16, 1997.

ARTES, F.; CASTANER, M.; GIL, M.I. El pardeamiento enzimático en frutas y hortalizas minimamente procesadas. Food Science Research International, v.6, n.4, p.377-389, 1998.

BRYANT, P. Optimising the postharvest management of lychee (Litchi chinensis Sonn.) - a study of mechanical injury and desiccation. 2004. 397f. Thesis (Doctor of Philosophy) - Department of Crop Sciences, University of Sydney, Sydney, 2004. 
CHEN, W.; WU, Z.; JI, Z.; SU, M. Postharvest research and handling of litchi in China - a review. Acta Horticulturae, n.558, p.321- 329, 2001.

CHITARRA, M.I.F.; CHITARRA, A.B. Pós-colheita de frutos e hortaliças: fisiologia e manuseio. 2. ed. rev. e ampl. Lavras: UFLA, 2005. 785p.

DEL AGUILA, J.S.; HOFMAN, P.; CAMPBELL, T.; MARQUES, J.R.; DEL AGUILA, L.S.H.; KLUGE, R. A. Pré-resfriamento em água de lichia 'B3' mantida em armazenamento refrigerado. Ciência Rural, v.39, p.273-279, 2009.

FOYER, C.H.; DESCOURVIERES, P.; KUNERT, K.J. Protection against oxygen radicals: An important defense mechanism studied in transgenic plants. Plant Cell and Environment, v.17, p.507523, 1994.

HOJO, E.T.D.; DURIGAN, J.F.; YUKI HOJO, R.H.; DONADON, J.R.; MARTINS, R.N. Uso de tratamento hidrotérmico e ácido clorídrico na qualidade de lichia 'Bengal'. Revista Brasileira de Fruticultura, v.33, n.2, p.10-15, 2011.

LICHTER, A.; DVIR, O.; ROT, I.; AKERMAN, M.; REGEV, R.; WIESBLUM, A.; FALLIK, E.; ZAUBERMAN, G.; FUCHS, Y. Hot water brushing: an alternative method to $\mathrm{SO} 2$ fumigation for color retention of litchi fruits. Postharvest Biology and Technology, v.18, p.235-244, 2000.
MENZEL, C.M. The physiology of growth and cropping in lychee. Acta Hoticulturae, v.558, p.175-184, 2001.

MINOLTA CORP. Precise color communication: color control from feeling to instrumentation Ramsey: Minolta Corporation Instrument Systems Division, 1994. 49p.

MIZOBUTSI, G.P.; FINGER, F.L.; RIBEIRO, R.A.; PUSCHMANN, R.; NEVES, L.L.M.; MOTA, W.F. Effect of $\mathrm{pH}$ and temperature on peroxidase and polyphenoloxidase activities of litchi pericarp. Scientia Agrícola, v.67, n.2, p.213$217,2010$.

SAEG. Sistema para Análises Estatísticas, versão 9.1. Viçosa: Fundação Arthur Bernardes, UFV, 2007. CD Rom.

SILVA, D.F.P.; CABRINI, E.C.; ALVES, R.R.; SALOMÃO, L.C.C. Uso do ácido ascórbico no controle do escurecimento do pericarpo de lichia. Revista Brasileira de Fruticultura, v.32, n.2, p.618-627, 2010.

UNDERHILL, S.J.R., CRITCHLEY, C. Physiological, biochemical and anatomical changes in lychee (Litchi chinensis Sonn) pericarp during storage. Journal of Horticultural Science \& Biotechnology, v.68, n.3, p.327-335, 1993. 